\title{
O trabalhador-financista: uma síntese histórica da gestão dos contraditórios da identidade laboral nos fluxos financeiros
}

\author{
Ivan Jairo Junckes ${ }^{*}$
}

\section{Introdução}

A identidade dos trabalhadores bancários esteve historicamente fundada em três fatores: a definição formal-legal de sua categoria de trabalho desde os anos 1930, a evidência da vivência polarizada entre o empregador-banqueiro e o empregado-bancário, e a baixa permeabilidade das fronteiras que regulavam o sistema financeiro nacional até o final dos anos 80. Entretanto a dinâmica sócio-politica dos anos noventa promove vários questionamentos sobre os impactos das novas tecnologias de organização primária do trabalho implantadas nos bancos e da desnacionalização do setor bancário no Brasil sobre a estruturação identitária dos trabalhadores em instituições financeiras ${ }^{1}$. Este artigo contribui para aprimorar esta problemática abordando três fatores re-constitutivos da identidade dos bancários brasileiros: a redefinição da composição orgânica da categoria bancária, os novos mecanismos de subsunção desses trabalhadores no mundo das finanças e as alterações nas noções de territo-

\footnotetext{
*Faculdade União/Ponta Grossa/PR. Doutor em sociologia politica. ${ }^{1}$ Ver:

JINKINGS, Nise. Trabalho e resistência na "fonte misteriosa", os bancários no mundo da eletrônica e do dinheiro. Campinas (SP): Editora da Unicamp; São Paulo: Imprensa Oficial do Estado, 2002.

JUNCKES, Ivan Jairo. O sindicalismo novo dos bancários na reestruturação financeira dos anos noventa no Brasil. Florianópolis: UFSC. PPGSP (tese de doutorado), 2004. 
rialidade e temporalidade dos bancários decorrentes da reestruturação financeira ocorrida no país na virada do século.

A discussão realizada a seguir parte da concepção de que a crescente influência dos bancos no conjunto social instaura um novo regime de gestão dos contraditórios próprios do sistema de capital, cujas normas e instrumentos se estabelecem sobre os conflitos sociais e sobre a ordem pública, reduzindo ou neutralizando as resistências históricas dos seus setores assalariados. Os conglomerados financeiros passaram a coordenar territorialidades especificas que suplantaram os referenciais nacionais e consagraram a ordem fluida dos fluxos financeiros mundializados, gerando novos parâmetros para a subsunção real do trabalho no estrato financista ${ }^{2}$.

\section{A recomposição da categoria dos bancários: os estabelecidos e os outros}

Entre as principais alterações nas condições gerais de trabalho nos bancos, cujo impacto para a alteridade bancária é determinante, destaca-se a recomposição orgânica da categoria dos bancários mediante a acentuada redução no número de trabalhadores empregados das instituições bancárias e o exponencial crescimento do número de trabalhadores de empresas prestadoras de serviços para os bancos. O permanente esforço das corporações financeiras na con-

\footnotetext{
${ }^{2}$ Ver os estudos de:

CHESNAIS, François. A mundialização do capital. São Paulo: Xamã, 1996.

HARVEY, David. Los limites Del capitalismo y la teoria marxista. Ciudad Del México: Fondo de Cultura Econômica, 1990.

JUNCKES, Ivan Jairo. Territorialidades do capital bancário nacional e as redes financeiras globais no séc. XXI. In: Revista Terr@ Plural, v. 1, p. 39-65, 2007.

MINELLA, Ary Cesar. Banqueiros: organização e poder politico no Brasil. Rio de Janeiro-São Paulo: Anpocs-Espaço e Tempo, 1988.

Grupos financeiros e organização da burguesia financeira no Brasil. In: Ensaios FEE, ano 17, n. 2, 1996.

Grupos financeiros e associações de classe do sistema financeiro. In: $O$ Estado Brasileiro: Agências e agentes. Niterói: EdUFF/Vício de Leitura, 2005, p. 159-178.
} 
corrência intercapitalista implicou investimentos que, entre 1995 e 1998, consumiram 8,5\%, em média, do patrimônio dos bancos $^{3}$, para a intensificação da informacionalização dos serviços que, associados a outras tecnologias de neutralização de resistências e maximização da adesão ativa dos empregados, estavam destinados principalmente à eliminação ou precarização dos postos de trabalho nessas instituições ${ }^{4}$.

Até o início dos anos oitenta, os trabalhadores nãobancários em instituições financeiras eram fundamentalmente os vigilantes e pessoal de asseio e conservação predial; entretanto, nos anos noventa, generalizou-se a força-de-trabalho contratada por empresas terceirizadas, a contratação temporária ou mesmo a interposição fraudulenta de estágios sub-remunerados para os setores e serviços de apoio administrativo, digitação, apoio operacional de comunicações, teleatendimento, o front line nas agências e a maioria dos serviços de processamento de documentos e informações. A

${ }^{3}$ FEBRABAN/FENABAN - Federação Brasileira de Associações de Bancos. Balanço social dos bancos 1998. São Paulo: Fenaban, 1999, p. 19.

${ }^{4}$ Ver os trabalhos de:

ANTUNES, Ludmila Rodrigues. Reestruturação produtiva e sistema bancário: movimento sindical bancário brasileiro nos anos 90. Tese de Doutorado - Instituto de Economia da Universidade Estadual de Campinas - UNICAMP, 2001.

CARVALHO et alii. Desnacionalização do setor bancário e financiamento das empresas. In: Texto para discussão 822, maio de 2002. Brasília: IPEA, 2002.

COSTA, Fernanda H. R. A jornada de trabalho e as recentes transformações no setor bancário brasileiro. Dissertação em Economia. Curitiba: UFPR/Setor de Ciências Sociais Aplicadas, 2002.

DIEESE - Departamento Intersindical de Estatística e Estudos sócio-Econômicos. O programa de remuneração variável do Itaú - AGIR. São Paulo: Subseção Sese-Seeb São Paulo, 1997, mimeo.

. Marcas da reestruturação do setor bancário brasileiro pós-94: concentração, internacionalização, privatização e desemprego. São Paulo: Subseção CNB Bancários, 2000, mimeo.

JINKINGS, Nise. O Mister de Fazer Dinheiro: Automatização e Subjetividade no Trabalho Bancário. São Paulo: Ed. Boitempo, 1995.

JINKINGS, 2002, op. cit.

KREIN, José Dari; e GONÇALVES, José R. Barbosa. Mudanças Tecnológicas e seus Impactos nas Relações de Trabalho e no Sindicalismo do Setor Terciário. IN: O Trabalho no Setor Terciário: Emprego e Desenvolvimento Tecnológico. São Paulo: DIEESE, 2005, p. 193-218.

180 Revista de História Regional 14(2): 178-205, Inverno, 2009 
heterogeneização crescente do mercado laboral, as alterações na tecnologia de organização do trabalho bancário e a distensão progressiva da legislação trabalhista proporcionaram a substituição acelerada da força-de-trabalho que, em dezembro de 1986, ocupava 842.188 bancários e foi reduzida em pouco mais de uma década em $52,5 \%$, passando para 400.021, em dezembro de 1999, enquanto as empresas prestadoras de serviços e alocação de estágios realizaram o acréscimo de aproximadamente 260.000 trabalhadores nas mais diversas áreas bancárias ${ }^{5}$.

Expoentes de resistência e das conquistas nos anos do novo sindicalismo, os bancários desenvolveram uma complexa capacidade tática para sobreviver aos ataques governamentais, à transnacionalização do capital, à crise do emprego formal na categoria e à ideologização que promoveu mudanças nos parâmetros identitários dos trabalhadores no sistema financeiro. Nos anos noventa, preservaram elevados os índices de sindicalização relativa apesar da redução, pela metade, no estoque de emprego formal nos bancos. Tal façanha só foi possivel porque os sindicatos dispensaram do cálculo os terceirizados e continuaram representando estritamente aqueles trabalhadores formalmente reconhecidos como tal pelos empregadores. Krein e Gonçalves ${ }^{6}$ confirmam em estudo comparativo entre diversas categorias de trabalhadores organizados o heterogêneo recuo nas conquistas sindicais e a acentuada diferença constituída entre trabalhadores bancários e não-bancários prestadores de serviços em bancos ou corporações financeiras, especialmente nos mecanismos de flexibilização, ou mais propriamente, de descumprimento da legislação trabalhista básica. Assim, determinadas frações entre os bancários transigiram um declínio progressivo das suas condições gerais de contratação do trabalho em detrimento de outras frações que tiveram suas condições rapidamente precarizadas para atenuar as exigências

${ }^{5}$ Dados do Mapa de Emprego Bancário no Brasil - Dieese e do Cadastro Geral de Empregados e Desempregados - CAGED/MTb (Lei 4923/65).

${ }^{6}$ KREIN e GONÇALVES, op. cit. p. 193-218. 
da massa salarial a cargo dos financistas. O contexto destas medidas é assim descrito por Gonçalves et al:

[...] os bancos conseguiram implementar importantes mudanças na forma de gestão da mão-de-obra e de reorganização do trabalho bancário, apesar de toda a tradição de luta e organização da categoria. Por exemplo, houve transformações significativas em aspectos centrais da regulamentação do emprego sem passar pela negociação com o sindicato, tais como: a introdução de inovações tecnológicas e organizacionais, os planos de metas, a intensificação do ritmo de trabalho, o trabalho comissionado de 8 horas, o processo de despedida dos empregados e a terceirização. ${ }^{7}$

Por essa forma ampliaram-se as condições de subsunção do trabalho no capital através do estabelecimento de um amplo estrato periférico de força-de-trabalho precarizada e da preservação de um núcleo de bancários integrado aos objetivos estratégicos da corporação, aos quais é conferida, de maneira escalar e concentrada, parcela da margem contábil obtida com a terceirização.

Extensa documentação sobre a terceirização no sistema financeiro, organizada pela Confederação Nacional dos Bancários - CNB/CUT ${ }^{8}$, predecessora da Confederação Nacional dos Trabalhadores do Ramo Financeiro da CUT - CONTRAF/ $\mathrm{CUT}^{9}$, registra a prática generalizada de formação de grandes empresas prestadoras de serviços, legalmente constituídas e operantes, cujo acionista majoritário e o principal cliente é uma instituição bancária que se utiliza desse artificio legal para pagar salários reduzidos, exigir jornadas superiores a doze horas e burlar de todas as formas os direitos trabalhis-

\footnotetext{
${ }^{7}$ GONÇALVES, José Ricardo B. et al. Condições de trabalho e sindicalismo no setor bancário no Brasil. In: As transformações no mundo do trabalho e os direitos dos trabalhadores. São Paulo: LTR, 2006, p. 114.

${ }^{8}$ Documento denominado Relatório da Terceirização no Sistema Financeiro, de junho de 2001, mimeo da Confederação Nacional dos Bancários - CNB/CUT.

${ }^{9}$ A Confederação Nacional dos Trabalhadores do Ramo Financeiro da CUT CONTRAF/CUT sucedeu a Confederação Nacional dos Bancários - CNB/CUT, em 2006. Dentre outros motivos, a mudança foi orientada pela busca do reconhecimento e registro sindical abrangendo bancários, financiários, securitários, empregados de bolsas de valores, entre outros não considerados bancários.
} 
tas básicos, conforme descrito por um ex-bancário ${ }^{10}$, demitido após doze anos de trabalho e recontratado sucessivamente por quatro empresas prestadoras de serviço nos últimos seis anos:

O que mudou é que quase não existe mais bancário para serviço de apoio, nós fomos todos terceirizados; claro que para quem ficou no banco em relação ao mercado eles estão bem até enquanto estiverem lá, depois é dureza que todo mundo de lá morre de medo: salário que chega a até $\mathrm{R} \$ 270,00$, com ticket de $R \$ 7,00$ descontando $20 \%$, entra as 15 horas e sai só quando terminar o expediente, nunca sabe quando sai e também nunca se paga hora extra, frequentemente chega a 12 ou 14 horas de trabalho com um lanche de uns 15-20 minutos. E é assim ó: 'se quer, quer, se não quer tem quem queira', é o que a gente mais ouve e tem que aceitar porque sabe que tem quem queira mesmo e pronto. Informação? petecas, nem da empresa nem de ninguém, não sei do dono, da sede, do número de funcionários, onde mais atua, o que mais faz, não sabemos nada, só quando quebra e o dono fecha, aí tem falatório de todo lado mas também não dá em nada.

No discurso desse trabalhador evidenciam-se os elementos de precarização do trabalho, fundamentalmente vinculados à diversificação das experiências sobre o tempo e à instauração do medo como propulsor da esquiva que segmenta os trabalhadores. O impacto mais significativo dessa estratégia de organização primária do trabalho na composição identitária dos bancários pode ser caracterizado, seguindo os estudos de Elias em Os estabelecidos e os outsiders ${ }^{11}$, pela reconfiguração das relações intraclassistas vividas pelos trabalhadores em bancos. Tal dinâmica de diferenciação identitária entre bancários e terceirizados e mesmo entre es-

\footnotetext{
${ }^{10}$ Os trechos transcritos neste texto foram obtidos em entrevistas realizadas entre outubro de 2001 e março de 2002 com 29 empregados(as) em instituições bancárias, dentre eles(as) dirigentes e representantes patronais, militantes e dirigentes sindicais. A lista dos entrevistados(as) pode ser obtida em JUNCKES, 2004, op. cit.

${ }^{11}$ ELIAS, Norbert. Os estabelecidos e os outsiders: sociologia das relações de poder. Rio de Janeiro: Ed. Jorge Zahar, 2000.
} 
ses últimos pode ser assim representada conforme as figuras a seguir:

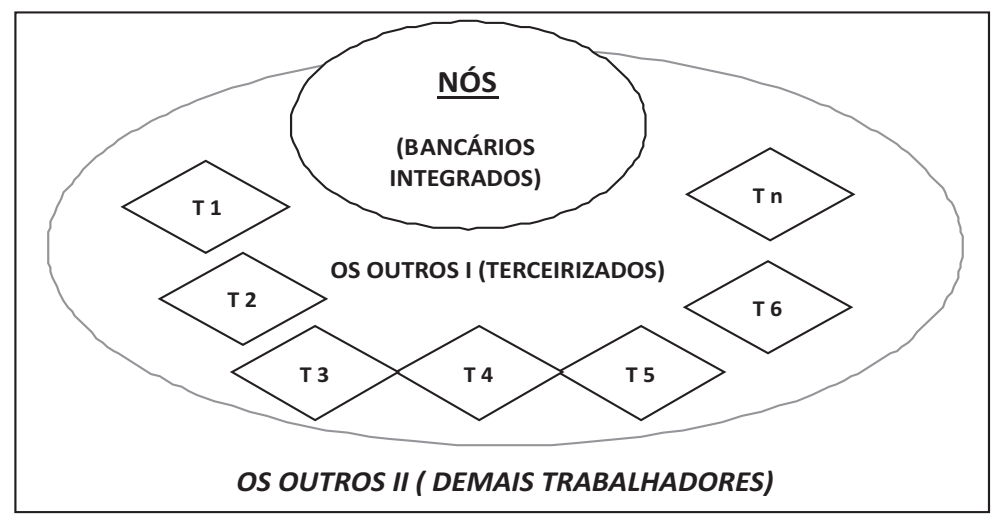

Figura 1: Reconfiguração de identidade por gradientes de integração entre os bancários, os terceirizados e os demais trabalhadores.

Elaboração: autor

A figura anterior representa o posicionamento relacional dos bancários remanescentes dos processos de terceirização que constituem um nós específico a partir dessas experiências e configuraram para os terceirizados o papel do outro, assumido e confirmado por esses trabalhadores que reconfirmam a posição central dos bancários. Constituem-se assim graduantes de integração, entre os trabalhadores em geral, os terceirizados e os bancários que permanecem integrados diretamente aos bancos.

Outros elementos, além das condições já apontadas anteriormente, para a constituição da alteridade dos bancários podem ser observados no discurso patronal de um gestor financista já em 1996: "Terceiriza-se mão-de-obra, não inteligência" ${ }^{2}$. O que se revela nessa expressão patronal é o aprofundamento das diferenças na natureza do trabalho

\footnotetext{
${ }_{12}$ Declaração de Alex Zornig, diretor de finanças Banco de Boston, extraída da reportagem Bancos testam novas formas de terceirização, publicada no Jornal Gazeta Mercantil, em 19/02/1996. 
advindas da informacionalização. Em movimentos opostos, o trabalho imaterial estabelece um núcleo com ocupações que incorporam tarefas analíticas e simbólicas e uma ampla periferia à qual se destinam tarefas de manuseio e processamento de dados rotineiros. Na dinâmica do trabalho imaterial os bancários inteligentes, aqueles sobreviventes e agentes diretos da financeirização, são relativamente isolados dos prestadores de serviços, conforme relato de um bancário com dezenove anos de serviços:

O Santander não contamina o ambiente bancário com a terceirização, o banco estabelece espaços específicos, uma casa ou um andar inteiro de um prédio, e ali se fazem todos os serviços terceirizados do banco, tudo controlado por um ou dois funcionários do banco, onde as terceiras trabalham, às vezes em parceria com outros bancos esse espaço é mantido longe da agência, dos bancários mesmo, no banco mesmo a gente não encontra terceiros que é para não complicar, misturando as coisas às vezes um ou outro estagiário só.

O discurso dos bancários incorpora e reproduz a diferenciação identitária quando identifica sistematicamente a condição de externalizado para os prestadores de serviços nas atividades coletivas, nos boletins, teses e deliberações associativas, tal qual pode ser observado na declaração de um dirigente sindical bancário, com 27 anos de banco, que ressalta consciência superior dos bancários em relação aos outros terceirizados:

Tem uma coisa: nas paralisações esse é o pessoal que mais tem pressionado para entrar no banco, impressionante como esse pessoal não tem uma consciência como o bancário tem, eles choram querem pular muro, reclamam e querem entrar a qualquer custo. Então até aí nós temos dificuldade de conversar com esse pessoal.

A referência a esse pessoal é comum em diversas falas de bancários e reproduzida no discurso de outro dirigente sindical, com doze anos de trabalho, que expressa acentuada acomodação com a diferenciação promovida pela política patronal e se referencia no distanciamento estabelecido entre os estratos de trabalhadores: 
A primeira questão é: dá pra reverter essa terceirização? Não, não dá e o banco já tem isso decidido porque quer esse pessoal para trabalhos específicos e ganhar com isso. O que nós queremos agora é aproximar esse pessoal dos bancários, o que interessa é essa aproximação, nós até queríamos é que fossem bancários como nós mas não tem jeito, a negociação está parada porque o banco na mesa pergunta: então porque vocês acham que eu estou terceirizando se é para continuar bancário.

O discurso patronal e a constituição identitária dos bancários formalmente empregados em instituições bancárias são reconhecidos e confirmados pelos trabalhadores em empresas prestadoras de serviços em bancos, tal qual evidenciado na fala de um prestador de serviços que foi bancário durante dez anos:

Entre o pessoal das terceiras o pessoal é solidário, tem poucos conflitos porque a gente sabe que se sair de uma terceira não tem muito para onde correr senão ir para outra terceira, porque para o banco a gente não volta nunca mais e não pode esperar mais nada lá de dentro, só ferro deles pra nós porque é eles lá e nós aqui.

Interessante observar que a diferenciação de dentrofora também se reproduz entre os próprios terceirizados, representado na figura anterior por diferentes permeabilidades nas fronteiras de cada grupo, conforme a fala de um ex-bancário que destaca a particularidade de sua condição de terceirizado mensalista dentre seus iguais terceirizados horistas:

Eu sou mensalista, graças a Deus. Os outros $90 \%$ dos funcionários são horistas, tem muita diferença. O horista ganha por produção (...) trabalha dez horas com uma de descanso, chegando freqüentemente a doze ou até mais dependendo se o cara agüenta, final de semana e feriado ele não ganha, não é aceito o atestado médico apresentado pelo horista, se ficar doente nem adianta trazer atestado, perde o dia. Então a mão-de-obra é realmente escravizada numa terceira, claro que isso eu só posso falar aqui lá eu não falo, nem posso pensar em falar coisa assim. Tive a felicidade de ser contratado. Quando eu trabalhava no banco [oito anos] eu nunca sabia 
se eu era um bom profissional, hoje eu sou valorizado porque a possibilidade de crescimento dentro de uma terceira é maior, aquele que realmente é bom profissional encontra portas abertas para organizar o grupo de trabalhadores, eu saio tarde na madrugada e um motorista me leva em casa e no outro dia eu posso chegar mais tarde, hoje eu só não aceitaria ser horista, mas como mensalista eu tô melhor...

Desta forma, com a terceirização, os financistas realizaram simultaneamente a fragmentação das diferentes posições ocupadas pelos trabalhadores em bancos e sua articulação em uma rede corporativa que gerou graduantes de integração dessas diferenças como elemento propulsor do lucro, estabelecendo assim disputas intra-classes através de uma hierarquização entre os trabalhadores integrados aos núcleos financeiros e os demais terceirizados.

\section{A constituição do trabalhador-financista nas novas formas de remuneração e convencimento}

As novas formas de remuneração variável do trabalho dos bancários que permanecem integrados à dinâmica central da produção da riqueza financeira, fundamentalmente vinculadas ao desempenho individualizado na geração da lucratividade da instituição, são o segundo fator a ser considerado para análise das recentes alterações nas condições identitárias dos bancários. Desde o início dos anos noventa os valores fixos da remuneração dos trabalhadores bancários têm sido progressivamente reduzidos enquanto parcelas variáveis têm avançado rapidamente na composição total da remuneração ${ }^{13}$.

${ }^{13}$ Ver os trabalhos de:

ANTUNES, op. cit.

COSTA F., op. cit.

DIEESE, 1997 e 2000, op. cit.

JINKINGS, 1995 e 2002, op. cit.

PASSOS, Daniel Domingos dos. A internacionalização do setor bancário no Brasil após o plano real: divergências de interesses dos banqueiros com a ação do Estado e mudanças nas negociações com os trabalhadores bancários. Departamento de Sociologia da Universidade Federal do Paraná (Dissertação de mestrado) - UFPR, 2001. 
O Balanço Social publicado pela Federação Nacional dos Bancos - FENABAN/FEBRABAN, edições entre 1993 e 2006, demonstra que o salário básico dos bancários foi reduzido em 17\% entre 1993 e 1999, enquanto o salário geral médio nos bancos aumentou $88 \%$ no mesmo periodo ${ }^{14}$. Isso não significa que os escriturários estejam recebendo menos e estratos gerenciais tenham tido aumentos reais tão expressivos, contrariando os acordos coletivos firmados no período, mas que os valores não pagos na condição de salário básico, piso fixo dos bancários, passaram a ser pagos como remuneração variável. Dados das demonstrações contábeis consolidadas do Banco Itaú permitem concluir que, desde 2000, a parcela variável do salário corresponde em média a $40 \%$ da remuneração líquida média dos empregados do banco e, se for considerado que esses valores têm uma distribuição acentuadamente heterogênea, pode-se encontrar parcelas de empregados cuja remuneração variável representa, dependendo do seu desempenho em relação às metas e resultados, diversas vezes a parcela fixa.

O contingente relativo de bancários envolvidos na remuneração variável - RV -apresenta crescimento acelerado nos últimos anos. Em 1999, pouco mais de um terço dos bancários participava dos programas de RV. Em 2003 participaram dos programas de participação nos resultados aproximadamente dois terços da categoria, e, em 2006, foram 414 mil bancários, ou quase a totalidade. Considerando-se o valor total distribuído em 2006, R\$2,68 bilhões, cada bancário recebeu, em média, $R \$ 6,5$ mil em salário variável, correspondente a quase oito vezes o salário-base da categoria vigente em 2006. Considerando novamente que a distribuição destes valores apresenta acentuada heterogeneidade, em muitos casos o salário variável supera o montante recebido em salário-base.

Fruto desta relação material e da ideologização promovida pela remuneração variável, observa-se entre os bancá-

\footnotetext{
${ }^{14}$ As publicações entre 2000 e 2006 não mais permitem o comparativo realizado nas edições anteriores. 
$\operatorname{rios}^{15}$ a crescente demanda por uma maior participação dos trabalhadores na definição dos critérios dos programas de remuneração variável, tais como a definição das metas e da parcela a ser distribuída, fundamentalmente para acompanhar as manobras administrativas e contábeis no pagamento dos valores, tal qual expresso em jornal sindical durante a campanha salarial de 2006: "BB aceita formato de PLR e vai pagar, porque os outros bancos discriminam? Apesar dos recordes de lucratividade maior parte dos bancos emperra negociação e só paga participação milionária para altos executivos" 16 .

Embora a participação nos mecanismos de lucratividade e remuneração variável seja pouco questionada no seu mérito, observa-se também uma parcela do discurso sindical denunciando face nefasta da realização das metas e resultados, conforme pode ser observado na declaração de um bancário com dezesseis anos de banco:

Antes [no tempo do Bamerindus] participar nos lucros era até bom porque a gente via o lucro no banco e recebia uma parte, menos do que a gente sempre queria claro, agora tem o PPR que é mais uma forma de exigir mais trabalho de cada bancário que uma participação em resultados, antes o pessoal corria para fazer lucro, hoje corre para escapar do rebaixamento da agência, corre para escapar da demissão por apresentar pouco resultado, tá sempre fugindo de algo de ruim que pode acontecer se não trabalhar tanto quanto o banco espera, quando vem a grana a gente tá doente, quase maluco com a sensação de ter fugido que chega e não de ter construído qualquer coisa.

Algumas pesquisas de opinião realizadas com os bancários revelam também uma elevada concordância e satisfação com os programas de remuneração variável. Pesquisa

\footnotetext{
${ }^{15}$ Análise documental realizada nas teses e deliberações de congressos sindicais, em textos de diversas entidades sindicais e, especialmente, em centenas de edições do tablóide Folha Bancária, editada pelo Sindicato dos Bancários de São Paulo.

16 Jornal dos Bancários, Confederação Nacional dos Trabalhadores do Ramo Financeiro - CONTRAF, ago/2006.
} 
contratada pela Federação dos Trabalhadores em Empresas de Crédito do Paraná - FETEC-PR/CUT ${ }^{17}$ para avaliar os impactos do Programa de Participação nos Resultados do HSBC no Paraná conclui que $77 \%$ dos entrevistados consideram o PPR ótimo ou bom enquanto apenas um quarto dos entrevistados relata mudanças negativas com a introdução do programa, como maior cobrança e maior controle, e apenas $15 \%$ relata maior competição, $10 \%$, mais trabalho e tão somente $8 \%$ considera maior o risco de demissão. Outra pesquisa realizada pelo Banco Itaú ${ }^{18}$ com 23.859 funcionários da instituição conclui que $79 \%$ dos entrevistados declararam-se satisfeitos com os procedimentos de remuneração adotados pelo banco. Adicionalmente, a pesquisa do Itaú revela índices de satisfação de $77 \%$ com a carreira oferecida pelo banco, $77 \%$ satisfeitos com o ambiente de trabalho, $89 \%$ satisfeitos com a organização (corporation), 88\% satisfeitos com os valores corporativos e $96 \%$ manifestaram-se satisfeitos com a Visão Itaú: "Ser o banco líder em performance, reconhecidamente sólido e confiável, destacando-se pelo uso agressivo de marketing, tecnologia avançada e por equipes capacitadas, comprometidas com a qualidade total e a satisfação dos clientes".

Intensos programas de treinamento e comunicação com os empregados complementam os processos de convencimento dos bancários e a obtenção da dedicação requerida pelas plataformas operacionais corporativas. Segundo dados da FEBRABAN ${ }^{19}$, o número de participações em atividades de treinamento passou de 640 mil, em 1993, para 1 milhão, em 2001, e para 1,68 milhões, em 2006, superando no total 25 milhões de horas de treinamento, não incluída aí a autocapacitação com tutoriais digitais que nos maiores ban-

\footnotetext{
17 Avaliação do Programa de Participação nos Resultados do HSBC - Pesquisa quantitativa com aprofundamento qualitativo realizada pela GLOBL Pesquisas e Planejamento entre fevereiro e abril de 2000.

${ }^{18}$ Pesquisa Fale Francamente, coordenada pela Diretoria de Desenvolvimento das Pessoas e divulgada em março de 2002.

${ }^{19}$ Dados obtidos nos Balanço/Relatório Social dos Bancos - FEBRABAN nos respectivos anos.

190 Revista de História Regional 14(2): 178-205, Inverno, 2009
} 
cos tem ocupado aproximadamente três horas semanais de cada funcionário, enquanto os novos empregados em treinamento têm esse tempo estendido para todos os dias durante os primeiros meses. Se considerarmos que, em 1993, havia 671 mil bancários empregados, obter-se-á a média de uma atividade de capacitação por trabalhador naquele ano em contraste com a média de 2,6 atividades para cada um dos 402 mil bancários, em 2001, e quase quatro atividades para cada um dos 425 mil bancários, em 2006, as quais ainda são complementadas pelo autotreinamento realizado nos ambientes virtuais.

No Banco HSBC, o programa de treinamento do primeiro ano do empregado é composto de diversas etapas, e, já no primeiro dia de trabalho, o bancário recebe um amplo kit do treinamento que será seu objeto de estudo pelos trinta dias iniciais, os quais são monitorados diariamente pelo gestor da unidade mediante um plano de aprendizado onde conta a descrição minuciosa das tarefas do novo funcionário. Segundo o caderno do funcionário, é objetivo do programa avaliar se o novato identificará com clareza os valores, princípios e políticas do banco, os padrões de conduta requeridos pela organização, o perfil do profissional HSBC e, em último tópico, seus direitos e responsabilidades. O kit de iniciação é composto de um caderno texto, diversas fitas de vídeo e material explicativo sobre os conteúdos que o iniciante deverá compreender. Dentre eles destaca-se o guia Administrando o Tempo, onde constam as regras de controle e diversos exercícios para reduzir a duração das tarefas rotineiras, e o guia Managing for Value e Eu, cujo conteúdo fundamental são as possibilidades de o novo empregado obter vantagens competitivas para o Grupo, entre as quais destaca-se: "O MFV ajuda a garantir os empregos existentes e criar novas oportunidades". A apresentação desse último caderno é feita com a seguinte mensagem do presidente do HSBC:

O mundo está mudando e precisamos mudar com ele - só progredindo poderemos ter êxito nos mercados extremamente competitivos em que operamos. Por reconhecer essa necessidade o Grupo adotou uma nova estratégia: o Managing 
for Value - O HSBC no século XXI, que nos ajudará a utilizar a energia, a criatividade e as aspirações que já existem dentro do HSBC para transformar o Grupo. (...)

O Managing for Value estará no âmago de tudo o que fizermos - vai mudar o seu modo de trabalhar e também o meu. ...absorva seus ensinamentos e os ponha em prática, pois com o envolvimento e o comprometimento totais podemos fazer do HSBC a maior organização de serviços financeiros do mundo. ${ }^{20}$

O envolvimento dos funcionários com os propósitos corporativos é confirmado com admiração por um dirigente sindical bancário que denuncia em sua fala o quanto a liberdade de ação dos trabalhadores está condicionada aos novos padrões de desempenho e às necessidades básicas da concorrência:

O banco diz assim que o cara é importante para o banco, que ele é bom e inteligente para aprender novos conhecimentos e qualquer pessoa gosta disso, todos gostam de ser valorizados... Todos os dias o banco está lá trabalhando a mente, a cabeça, o sonho do bancário dizendo: meu amigo depende de você, da sua capacidade, do seu desempenho porque nós confiamos que você consegue e você merece, isso mexe muito com muita gente. Tivemos um caso onde após um trabalho de motivação o pessoal da agência formou equipes e se revezavam vendendo produtos no calçadão, viraram camelôs literalmente, e o sindicato teve que intervir e o pessoal ainda respondendo que quem sabia o limite e até onde eles podiam ir eram eles mesmos e que nós não devíamos nos meter nisso...

Os recursos informacionais que possibilitam aos bancos o acesso permanente e imediato aos bancários são fatores decisivos para a formação continuada do convencimento dos trabalhadores. Em todos os grandes bancos o dia do bancário somente é iniciado após o registro eletrônico de presença que inclui o ciente eletrônico no informativo diário, o qual é repetido diversas vezes como controle e alerta para

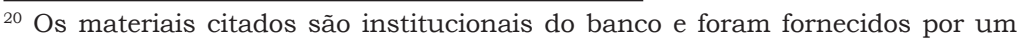
funcionário treinado do programa. 
as necessidades corporativas. Além do informativo diário, os bancos dispõem, ainda em modo digital, de normativos, circulares, intranet com correio eletrônico e publicações diversas voltadas a destacar aqueles funcionários mais dedicados e alimentar o clima motivacional adequado às necessidades corporativas. Tais recursos são assim descritos por um bancário:

O banco tá muito agressivo, ousado mesmo, mesmo que você não queira o banco ta ali do teu lado, junto, em baixo, em cima de todo jeito. No HSBC agora tem aquela revista, as cartas do presidente chegam mais identificadas com os funcionários porque o banco trabalha com a concepção de enaltecer o ego do funcionário, da equipe da agência que alcançou as metas e daí todo mundo quer aparecer na revista para todo o banco, parece que eles entendem bem como é que o bancário pensa e o que ele sente para fazer notícias onde o pessoal quer aparecer lá como se fosse com ele que tivesse acontecido para ele aparecer para todo mundo.

Com o estabelecimento de todos esses mecanismos de motivação e controle, ou de autocontrole, os trabalhadores realizam cotidianamente o culto da excelência incorporando progressivamente os principios da competitividade e o papel de guardiões da qualidade e da produtividade do trabalho bancário ${ }^{21}$.

As novas formas de remuneração, de treinamento do trabalho e de comunicação com os bancários compõem, como a parte mais perceptivel, um novo modelo de gestão de recursos cultivado nos bancos no qual a força de trabalho obediente e fixa, vigente até os anos setenta, foi transmutada pela disciplina híbrida, móvel e autocontrolada. Todas essas transformações ampliam exponencialmente o poder dos bancos nas relações de trabalho e afetam diretamente as condições para a organização de interesses dos bancários e sua capacidade de ação coletiva, potencializando radicalmente os impactos da dinâmica neoliberal sobre o sindicalismo.

${ }^{21}$ Ver especialmente JINKINGS (2002), op. cit. 
Entretanto tais inovações não excluem práticas bastante arcaicas e distantes da imagem baseada em uma relação puramente econômica, em que os resíduos patriarcais e do politicismo pré-capitalista estariam superados. Exemplo dessa contradição pôde ser vivido pelos empregados do HSBC na chegada do banco ao Brasil, em 1997, conforme relato de um funcionário:

$\mathrm{O} \mathrm{RH}$ de primeiro mundo do HSBC começou se apresentando aos funcionários com uma carta ${ }^{22}$, que o pessoal teve que assinar, dizia lá para os bancários tomarem banho antes de vir para o trabalho para não cheirar mal, é sim e foi assim mesmo pode ver, cortar o cabelo todo mês, pentear todo dia, fazer a barba, cortar a unha e até escovar os dentes e fazer necessidades fisiológicas antes de se apresentar na agência. Um absurdo.

Outra demonstração da capacidade de administração de padrões híbridos que rege as corporações financeiras foi o escândalo provocado pelas denúncias de contratação de delegados e policiais militares pelo HSBC para espionagem, infiltração de pessoal, suborno e escutas telefônicas ilegais realizadas em entidades sindicais e credores duvidosos do banco, nos anos de 1997 e 1998. O caso foi amplamente divulgado na imprensa, em maio e junho de 2001, e motivou trabalhos da CPI da Telefonia na Assembléia Legislativa do Paraná e inquéritos policial-militares nas polícias civil e militar do Estado do Paraná ${ }^{23}$.

Dessa forma, após as experiências de remuneração variável e participação nos lucros, dos intensos programas de treinamento e dos mecanismos de difusão da ideologia corporativa que dilaceraram as fronteiras constituídas histori-

\footnotetext{
${ }^{22} \mathrm{O}$ memorando e seu conteúdo foram objeto de reportagem Banco lança regras de higiene, publicada no jornal Folha de São Paulo, em 10 de junho de 1997.

${ }^{23}$ Matérias publicadas nos jornais Gazeta Mercantil, Folha do Paraná, Folha de São Paulo, Gazeta do Povo e outros entre 30 de maio e 17 de junho de 2001. Toda a documentação está em protocolo de inquérito do Banco Central, número 0001055969, motivado por comunicações jurídicas realizadas pela corregedoria da Polícia Militar do Paraná, durante o ano de 2000, ocorridas em virtude do envolvimento de militares no caso.
} 
camente pelos trabalhadores, os bancários integrados a essa nova dinâmica complexa e contraditória desenvolveram progressivamente atitudes de pensar e agir para o capital, assumindo a responsabilidade de ampliar os mecanismos necessários à acumulação financista. Essa participação ativa em um circuito essencialmente capitalista e seu correspondente interesse positivo na retenção de riquezas no estrato financista tem impacto direto na identidade dos bancários integrados, pois estes incorporam valores não compartilhados com os demais trabalhadores terceirizados e que os aproximam progressivamente de um perfil de gestor financista, conforme expresso em declaração da diretora da área de remuneração e eficácia do Citibank: "Eles acabam se dedicando como se fossem donos" ${ }^{24}$.

\section{A transformação da identidade territorial: a inserção global dos bancários nas redes do capital financeiro}

Além da recomposição orgânica da categoria e das novas tecnologias de gestão de pessoal, os fluxos do dinheiro e das finanças forçaram também uma acentuada recomposição nas referências espaciais de identidade dos trabalhadores em empresas cujos setores tornaram-se globais e cibernéticos.

As alterações nos referenciais identitários espaciais estão primeiramente atreladas à reestruturação produtiva e às tendências de imaterialização do trabalho que foram intensificadas com a concorrência interbancária nos anos noventa. A virtualização, formada pelos circuitos de impulsos eletrônicos, pelos centros de comunicação e pelas microrredes pessoais projetadas em macrorredes funcionais, promove entre os trabalhadores a ética da efemeridade das conquistas, aprofundando a exploração do trabalho e sufocando os

24 "Quando os beneficios se tornam algemas", Jornal Valor, 14/07/2000. Na mesma matéria registra-se a adesão de $75 \%$ dos 2.200 funcionários do Citibank no Brasil ao programa de compra facilitada de ações do banco. 
espaços de resistência à subsunção real promovida nos fluxos do capital ${ }^{25}$.

A informacionalização gera e é simultaneamente geradora de um novo registro de autoridade mediante a recriação e alocação de normas e instrumentos de coerção em espaços de fluxos ${ }^{26}$ que sustentam um estilo de vida produtor de novas formas materiais de suporte à dominação capitalista aprimorada com o ciclo neoliberal em curso, conforme discutido em Lima ${ }^{27}$. A intensa alocação de informações nas linhas dos fluxos e as novas formas de disciplinarização das resistências à exploração do trabalho desordenaram o tempo e os espaços historicamente apropriados pelos bancários, reorganizando o universo das relações desses trabalhadores.

No caso dos bancários brasileiros, pode ser observada uma profunda mudança nas condições de alteridade forjada pelo dilaceramento dos limites territoriais vigentes até os anos noventa, quando as fronteiras do espaço financeiro no Brasil estavam relativamente bem definidas e seus agentes relativamente identificados. Esse quadro foi rapidamente alterado com o aumento da participação dos bancos estrangeiros no sistema e a acentuada mudança no número de bancários empregados nesses bancos.

Em 1994, os bancos estrangeiros empregavam apenas 1,5\% do total de bancários do país. Em 2002, essa participação saltou para $18 \%$ e, em 2006 , ultrapassou $21 \%{ }^{28}$. Tal mudança correspondente a aproximadamente 90 mil ban-

\footnotetext{
25 Ver:

CASTELLS, Manuel. O poder da identidade. São Paulo: Paz e Terra, 2002, p. 22 -84 .

JINKINGS (2002), op. cit

${ }^{26}$ Espaços de fluxos são formas espaciais compostas por "sequências intencionais, repetitivas e programáveis de intercâmbio e interação entre posições fisicamente desarticuladas, mantidas por atores sociais nas estruturas econômicas, politica e simbólica da sociedade". Ver:

CASTELlS, Manuel. A sociedade em rede. São Paulo: Paz e Terra, 1999. p. 436.

${ }^{27}$ LIMA, Samuel Pantoja. Crime organizado e lavagem de dinheiro: uma aplicação das teorias dos jogos e de redes neurais para reconhecimento e descrição de padrões. Florianópolis: Programa de Engenharia de Produção (PPGEP) da Universidade Federal de Santa Catarina - UFSC (Tese de doutorado), 2005.

${ }^{28}$ Relatórios do BACEN: 50 maiores bancos, período do estudo.
}

196 Revista de História Regional 14(2): 178-205, Inverno, 2009 
cários que passaram a estar sob o comando de gestores estrangeiros, pois esses "novos bancários" são remanescentes das instituições nacionais incorporadas pelo capital externo. Essa alteração torna-se especialmente relevante pois esses trabalhadores que anteriormente eram empregados do capital nacional, passam a cumprir o papel de agentes imediatos da transição cultural e mercadológica inerente à troca no controle do capital bancário, conforme pode ser observado no relato de um bancário com doze anos de serviço:

Eu era funcionário do Bamerindus, era empregado do homem do chapéu [Andrade Vieira] que de vez enquanto até passava aqui na agência (...) De repente parece que ficou tudo chique e a gente tem que andar na linha, feito mauricinho senão o banco apresenta cartinha de advertência... Parece que ficou tudo muito grande, antes a gente tinha união entre a gente e o chapeludo que se explodisse, de repente o pessoal começou a defender um banco que nunca tinha visto na vida, elogiar e falar que agora é que ia pra frente porque era inglês de Hong Kong, e todo mundo se convenceu mesmo que era outra coisa.

A dimensão da mundialização do perfil do sistema apontada acima pelo entrevistado pode ser também percebida pela intensa reestruturação ocorrida no Banco Bamerindus após sua aquisição pelo Grupo HSBC, em 1997. Os dados comparativos do quadro a seguir, entre a condição do Banco Bamerindus, em 1993, e do Grupo HSBC, em 2003, auxiliam na compreensão das transformações vividas pelos trabalhadores que compuseram a transição entre as duas situações: 
Quadro 1 - Comparativo Banco Bamerindus 1993 e Grupo HSBC - 2003 - dados selecionados

\begin{tabular}{|c|c|c|}
\hline & BAMERINDUS DEZ / 1993 & Hsbc Dez / 2003 \\
\hline $\begin{array}{l}\text { Número de } \\
\text { funcionários }\end{array}$ & 31.325 no Brasil. & $\begin{array}{l}20.700 \text { no Brasil; } \\
218.000 \text { no mundo. }\end{array}$ \\
\hline Número de agências & $\begin{array}{l}1.323 \text { agências no Brasil; } \\
\mathbf{0 3} \text { agências no exterior. }\end{array}$ & $\begin{array}{l}925 \text { agências no Brasil; } \\
9.781 \text { agências em } \mathbf{7 9} \text { países. }\end{array}$ \\
\hline $\begin{array}{l}\text { Demais pontos de } \\
\text { atendimento }\end{array}$ & 1.127 PAB's no Brasil. & $\begin{array}{l}465 \text { PAB's no Brasil; } \\
\mathbf{4 , 3} \text { milhões de pontos de } \\
\text { atendimento eletrônico no mundo. }\end{array}$ \\
\hline Ativos totais & $\begin{array}{l}\text { R\$ } 30.350 \text { milhões (atualiz. } \\
\text { IGP-DI FGV p/ dez 2002)) }\end{array}$ & $\begin{array}{l}\mathrm{R} \$ 24.753 \text { milh / Brasil (dez/02) } \\
\text { R\$ 2.100.814 milh / mundo* }\end{array}$ \\
\hline
\end{tabular}

Fonte: Relatórios da Administração Bamerindus 1993, Relatórios financeiros HSBC Group 2000 e 2003, e Relatórios do Banco Central do Brasil - BACEN.

* Valores obtidos em dólares americanos e convertidos para Real na cotação de dez 2003.

Como pode ser observado no caso do Bamerindus, também os demais bancos nacionais adquiridos pelas corporações estrangeiras sofreram retração nos seus diversos indicadores específicos, tais como redução no número de agências e funcionários; entretanto o intenso crescimento do conjunto dos bancos estrangeiros em todos os segmentos do mercado de varejo financeiro transformou as relações entre os trabalhadores bancários e os referenciais de grandeza das corporações bancárias no país. Com a desnacionalização, as novas formas de regulação da gestão territorial financista promovem a realocação dos referenciais territoriais para o âmbito corporativo e a sujeição aos ditames verticalizados da mundialização financeira ${ }^{29}$. $\mathrm{O}$ ingresso dos bancos estrangeiros foi intensamente associado às noções de estabilidade, confiança, profissionalismo e sucesso que romperiam e superariam as práticas financeiras locais ${ }^{30}$. Essas associações

\footnotetext{
${ }^{29}$ Ver: CHESNAIS, op. cit.

${ }^{30}$ Para a precisão sobre os padrões de operação ver as análises sobre o ingresso e

198 Revista de História Regional 14(2): 178-205, Inverno, 2009
} 
reforçam circularmente a imagem de poder dos bancos estrangeiros, pois conforme Harvey:

Quem define as práticas materiais, as formas e os sentidos do dinheiro, do tempo ou do espaço fixa certas regras básicas do jogo social. ...Por essa razão, as materializações e significados atribuídos ao dinheiro, ao tempo e ao espaço têm uma grande importância no tocante à manutenção do poder político $^{31}$.

O esforço dos bancos para produzir sua imagem e sua inserção com padrões pretensamente superiores pode ser percebido nos intensos treinamentos de seus executivos para implantar os padrões mundializados nos bancos adquiridos no Brasil, conforme matéria jornalística de 1999:

O executivo que passou 14 meses em Londres tem objetivo de trazer para o País a cultura globalizada do banco inglês. O HSBC aposta na sofisticação gerencial proporcionada pela condição de participante do grupo muito restrito de bancos globais. Para tornar efetivo este diferencial, porém, é preciso mudar a maneira como o antigo Bamerindus era administrado. E para mudar a gestão, é preciso mudar as pessoas, ajudando-as a "adquirir uma visão de negócios do tamanho do HSBC", resume Schwertner. ${ }^{32}$

o desempenho dos bancos estrangeiros no Brasil realizadas em:

CARVALHO, et alii, op. cit.

CARVALHO, Fernando Cardim. The Recent Expansion of Foreign Banks in Brazil. In: Working Paper Series CBS-18-01. Oxford GB: University of Oxford Centre for Brazilian Studies, 2001.

DE PAULA, Fernando Rodrigues. Los determinantes del reciente ingreso de bancos extranjeros a Brasil. In: Revista de la CEPAL n ${ }^{\circ} 79$, abril 2003. Santiago de Chile: CEPAL, 2003, p. 169-188.

FREITAS, Maria Cristina Penido de. Abertura do sistema bancário brasileiro ao capital estrangeiro. São Paulo: Fundap : Fapesp; Brasília: IPEA, 1999.

IMF - INTERNATIONAL MONETARY FUND. International Capital Markets developments, prospects, and key policy issues. Washington: IMF/PS, 2000.

VIDOTTO, Carlos Augusto. O sistema financeiro brasileiro nos anos noventa, um balanço das mudanças estruturais. Campinas: Instituto de Economia da Universidade Estadual de Campinas (Tese de doutorado) - UNICAMP, 2002.

${ }^{31}$ HARVEY, David. A condição pós-moderna. São Paulo: Ed. Loyola, 1993, p. 207.

${ }^{32}$ Um profissional de RH em Londres, Jornal Gazeta Mercantil em 15/12/1999, p. C-3. 
A mundialização de pessoal citada pelo executivo do HSBC foi também realizada nos demais bancos que ingressaram no varejo brasileiro e enfrentaram o desafio de integrar os seus trabalhadores aos nós de suas redes corporativas mundiais como fator determinante para a sobrevivência na concorrência interbancária. Dessa forma, em poucos anos, milhares de bancários que eram empregados em bancos nacionais privados, públicos federais ou estaduais passaram a ser funcionários de bancos globais e seus principais agentes para realizar as estratégias definidas nas suas matrizes.

Os propósitos patronais estrangeiros foram reforçados pelos próprios bancários que, até a desnacionalização do sistema, compartilhavam com as noções de superioridade, como demonstra a declaração de um bancário que compara a gestão do Bamerindus, no qual trabalhava desde 1981, com a gestão mundializada do HSBC:

O Bamerindus era mais amador e nós conseguíamos mais coisas porque tudo era mais caseiro, qué vê então quando comparava com o pessoal que trabalhava nos estrangeiros mesmo da época, aí era uma diferença grande mesmo, lá tudo parecia profissional, o salário então... Hoje o HSBC só não tem o salário assim mas tem regras que a gente sabe que valem em boa parte do mundo e a gente aqui significa muito pouco para o banco fora das regras estabelecidas e do que interessa para o banco, eu aqui ou um outro cara no Japão pro banco é a mesma coisa, é trabalhar e dar lucro, meta pra cumprir e pronto.

A permeabilidade das fronteiras que diferenciavam os bancários empregados de bancos privados nacionais e também a mundialização dos referenciais de identidade tornaram residuais as diferenças entre os empregados em bancos estrangeiros e nacionais em operação no Brasil, conforme podem ser observadas no discurso de um dirigente sindical:

Há dez anos atrás tinha diferença sim, os estrangeiros tinham uma série de benefícios e o plano de remuneração era muito melhor e bem consistente, os estrangeiros eram o que poderíamos chamar de uma elite no sistema, hoje é que as diferenças foram suprimidas porque os diversos mecanismos 
de diferenciação foram deslocados todos para a remuneração variável que passa a ser a política padrão dos bancos.

O desenvolvimento dessas novas condições de alteridade teve grande impacto sobre o conjunto dos trabalhadores bancários, dispondo-os como agentes supranacionais produtores de riquezas fictícias nos fluxos financeiros globais e, como tais, ativamente inseridos nas conexões de rede dominantes da economia mundial. Entre os bancários o simbolismo da condição mundializada dos grandes bancos estrangeiros foi expressivo nos debates sobre a privatização do Banco do Estado de São Paulo - BANESPA, quando a aquisição do banco estadual paulista pelo banco espanhol Santander foi considerada "um mal menor" se comparada com sua aquisição pelo Itaú ou pelo Bradesco, fundamentalmente porque a coincidência de pontos de atendimento era menor e as relações de gestão são mais profissionais ${ }^{33}$. Essa mesma perspectiva é confirmada por uma bancária ao comparar os bancos nacionais e estrangeiros:

A diferença dos estrangeiros para os nacionais é que mesmo cumprindo todas as metas e tudo ele corre o risco de o banco quebrar, não se segurar no mercado, ser vendido ou coisa assim, isso ele sabe que num grande banco internacional não acontece, ele fica tranqüilo fazendo parte de um banco que tem no mundo todo porque sabe que o Santander não vai quebrar nunca, o Hsbc também não. É como tá acontecendo agora o pessoal do Bradesco e do Itaú com essa de o banco também vender uma parte, ou comprar nem sei direito, o que eu sei é que eles tão ficando grandes no mundo também e isso dá segurança sobre esses bancos depois de tudo que já se viu.

Dessa forma, a reestruturação bancária ocorrida no Brasil nos anos noventa rompeu as fronteiras da alteridade colonizada que, historicamente, estruturou a negatividade da identidade européia ou americana, mundializou os espaços

\footnotetext{
${ }^{33}$ Avaliações presentes em vários boletins sindicais no final de novembro e início de dezembro de 2000 e relato de entrevistas de sindicalistas nos jornais Gazeta Mercantil (21 e 22/11/00) e Folha de São Paulo (21,22 e 26/11/00).
} 
vividos nos fluxos do trabalho e constituiu temporalidades que estabelecem referenciais identitários híbridos, móveis e efêmeros. Conforme Hardt ${ }^{34}$, todas essas transformações provocam a indiferenciação do outro, colonizador e explorador da mais-valia presente no tempo comum, como condição fundamental para realizar a determinação imperial de superar as dualidades da modernidade e substituílas por gradientes de integração no sistema e de participação nos fluxos necessários à reprodução da ordem corporativa. A reconfiguração das condições de alteridade da categoria dos bancários é um movimento que mescla dominação, resistências e adesão à fragmentação dos referenciais locais que resultam no fortalecimento da verticalização das relações estabelecidas nos espaços de fluxos e afetam profundamente as condições gerais de organização dos interesses dos trabalhadores.

\section{Conclusões}

As transformações verificadas nos fatores constitutivos da identidade dos bancários - a redefinição da composição orgânica da categoria bancária, os novos mecanismos de subsunção desses trabalhadores no mundo das finanças e as alterações nas noções de territorialidade e temporalidade dos bancários decorrentes da reestruturação financeira ocorrida no país na virada do século - demonstram o aprofundamento das condições de hegemonia de classes estabelecidas nas novas formas de trabalho imaterial e abrigadas na dinâmica própria dos espaços de fluxos que suplementam as condições tradicionais de dominação.

O desenvolvimento do trabalho imaterial nos fluxos financeiros mundializados desconstitui as relações de tempo e espaço historicamente apropriados pelos bancários, reterritorializa o universo das relações desses trabalhadores e provoca uma intensa realocação de seus referenciais identitários. Esses fatores impulsionam as condições hegemônicas

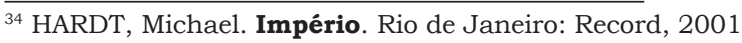


do capital e da consequente subsunção real do trabalho no estrato financista.

Confirma-se o trabalho bancário como um fenômeno social pleno de contradições e altamente produtivo, embora dependente e sujeito ao trabalho morto incorporado nas tecnologias informacionais; culto, embora gerindo um saber tão efêmero que pouco se deixa apropriar por seus operadores; auto-responsável, embora voltado às condições concorrenciais do mercado; emancipado, embora solitário em um contrato individualizado que o afasta das lutas históricas, e, finalmente, móvel e mundializado, embora estranhado ao cotidiano de seus proprietários e condicionado pelas necessidades de um espaço totalizante e de um tempo absoluto, tal qual apontava $\mathrm{Marx}^{35}$ nas regras básicas da subsunção real do trabalho no capital.

\section{Principais Fontes Sindicais}

Acordos e Convenções Coletivas de Trabalho entre a FENABAN e os sindicatos filiados à Confederação Nacional dos Trabalhadores em Empresas de Crédito CONTEC, entre 1987 e 2006.

Acordos e Convenções Coletivas de Trabalho entre a FENABAN e os sindicatos filiados à Confederação Nacional dos Bancários da CUT - CNB/CUT / Confederação Nacional dos Trabalhadores do Ramo Financeiro - CNTRAF, entre 1987 e 2006.

Balanço Social / Relatório Social dos Bancos - FEBRABAN/FENABAN, edições entre 1993 e 2006.

Jornal FOLHA BANCÁRIA. Sindicato dos Bancários de São Paulo - SEEB/SP, 492 edições entre julho de 1997 ( $n^{\circ}$ 3867) e junho de 2005 ( $n^{\circ}$ 4871).

Jornal FOLHA SINDICAL. Sindicato dos Bancários de Florianópolis SC e Região, 127 edições entre março de 1995 ( $n^{\circ}$ 293) e junho de 2006 ( ${ }^{\circ}$ 511).

Jornal O Bancário. Sindicato dos Bancários de Campinas SP e Região, várias edições entre abril de 1999 e outubro de 2003.

${ }^{35}$ MARX, Karl. Capitulo VI Inédito de O Capital, resultados do processo de produção imediata. São Paulo: Ed. Moraes, 1995, p. 87 - 108. 


\title{
O trabalhador-financista: uma sintese histórica da gestão dos contraditórios da identidade laboral nos fluxos financeiros
}

\author{
Ivan Jairo Junckes
}

Resumo: Este artigo analisa a estruturação identitária dos trabalhadores em bancos abordando três fatores re-constitutivos da identidade dos bancários brasileiros nas últimas décadas: a redefinição da composição orgânica da categoria bancária após a desnacionalização do setor bancário no Brasil, os novos mecanismos de subsunção desses trabalhadores no mundo das finanças e as alterações nas noções de territorialidade e temporalidade dos bancários decorrentes da reestruturação financeira ocorrida no país na virada do século. Com base em pesquisa bibliográfica, documental e entrevistas realizadas com dirigentes e representantes patronais, militantes e dirigentes sindicais, é apontada a constituição de um trabalhador agente do capital-trabalho que denominamos bancário-financista.

Palavras-chave: identidade; bancários; sindicalismo; sistema financeiro; bancos.

Abstract: This article analyses the structural identity of workers within bank institutions, engaging in three reconstitutive factors of Brazilian bank clerks identity in the last decades: a redefinition of the organic composition of the bank clerk category after the denationalization of the bank sector in Brazil, the new subjection mechanism of these workers in the finance world and the alterations of the territoriality and temporality notions of the bank clerks that originated from the finance restructuring that happened in the country in the turn of the century. Based on bibliographic research, documents and interviews with managers and representatives of the Banks board of directors, militants and syndicate directors, it is shown the constitution of an 
agent worker of the capital-labor that is denominated as a financier bank worker.

Keywords: identity; bank clerks; syndicalism; financial system; banks.

Artigo recebido para publicação em 09/03/2009

Artigo aceito para publicação em 22/06/2009 